\title{
Two forms of palilalia: a clinicoanatomical study
}

\author{
M. Ikeda and H. Tanabe \\ Department of Neuropsychiatry, Osaka University Medical School, Fukushima, Osaka, \\ 553 Japan
}

Correspondence to: $M$. Ikeda at above address

\begin{abstract}
The clinical and neuroradiological findings of three patients with marked palilalia due to different neurological disorders are reported. These cases and others in the literature suggest the possibility of different variations. "Spasmodic, heterophonic palilalia" is typically observed in Parkinson's syndrome and pseudobulbar palsy: the content of palilalia is characteristically changed by interruption. "Atonic, homophonic, autoecholalic palilalia" is mainly seen in Pick's disease, and is not affected by external interruption.
\end{abstract}

Keywords: Autoecholalia - Palilalia - Parkinsonism - Pick's disease - Pseudobulbar palsy

\section{INTRODUCTION}

According to Boller et al. (1973), palilalia was first described by de Renzi in 1879 and is the name given by Souques (1908) to a disorder of speech characterized by the compulsive repetition of a phrase or word which the patient reiterates with increasing rapidity and with a decrescendo of voice volume.

The clinical features and neuropathological lesions in reported patients with palilalia are not homogeneous. We report the clinical and neuroradiological findings in three patients who presented with palilalia due to different neurological disorders and discuss a possible clinical classification of dividing cases into sub-types.

\section{REPORT OF CASES}

\section{Case 1}

A 70-year-old right-handed man was admitted to hospital, on July 12,1989 , with a right hemiplegia and loss of consciousness. He had been followed up as an out-patient for hyperlipidaemia and transient cerebrovascular attacks.

In 1987, he developed an occipital headache on waking in the morning and a clumsy gait. A computed tomographic (CT) scan of the brain revealed a left parietal hemorrhage. Two months later, the headache recurred and another CT scan showed a new left parietotemporal hemorrhage. Over the next few weeks, he recovered and was able to return to work.

On admission, in 1989, a CT scan showed high density areas in the deep white matter of the left parietal lobe and the left lateral ventricle (Fig. 1a). In addition there was a small high density spot in the medial aspect of the right frontal lobe invading the cingulate gyrus. A cerebral arteriogram (four vessel study) showed a large avascular mass in the left parietal lobe but no etiologic factors such as vascular malformation and microaneurysms could be found. On the day of admission, this left hemispheral blood clot was surgically removed.

Postoperatively, he recovered slowly. Neuropsychological examination on August 14 showed that he was still mildly confused with poor recent memory and a short attention span. His speech was slightly palilalic and perseverative. Emotional incontinence was present. A CT scan (Fig. 1b) revealed low density areas corresponding to those seen pre-operatively and a subdural effusion in the left frontal region. A single photon emission computed tomographic (SPECT) scan with ${ }^{123}$ I-isopropyl-p-iodoamphetamine revealed reduced uptake in the left parietal lobe and in the right medial frontal region. Several days later he became delirious. A CT scan on August 25 disclosed a new small hemorrhage in the left medial frontal lobe encroaching on the straight gyrus and anteroinferior part of the cingulate gyrus (Fig. 1c). In a few days, he improved enough to be re-examined neuropsychologically. At that time, he showed marked palilalia both in spontaneous speech and in reply to questions. This symptom continued until he was transferred to another hospital in December, 1989.

Neurological examination in October revealed a right sided hemiplegia with sensory loss. He had lead pipe rigidity in his left arm and leg. There was a right homonymous hemianopia. Dysarthria and mild difficulty in swallowing were present. Snout reflex, sucking reflex, visual rooting reflex, and bilateral forced grasping brisker on the right 
were elicited. He had little change of face expression but sometimes developed emotional incontinence or forced crying when he was addressed.

It was difficult to evaluate the language disturbance because of dementia or psychomotor deterioration. Nonetheless, his language impairment characterized by poor comprehension and remarkable reduction of spontaneous speech output with echolalia and completion phenomenon representing his well-preserved repetition ability, allowed us to make a diagnosis of mixed transcortical aphasia. Verbal paraphasic errors were occasionally noted without literal paraphasia.

In addition to the aphasic features, palilalia and echopalilalia was conspicuous. He was, however, mute whenever left alone. Palilalia was observed in his sporadic spontaneous speech, but it became more evident in the form of (b) echopalilalia when we addressed him. He reiterated a syllable, syllables or a word two to 11 times, but repetition of phrases was not so frequent as that of syllables or words. As he repeated, the rate of speech gradually increased and the loudness reduced, but "palilalia aphone" (Marie and Lévy, 1925) was not apparent. Secondary symptoms such as facial grimacing and eye blinking were absent. Four types of reiteration were identified as follows:

(1) reiteration of a syllable at the beginning of words (which could be alternatively regarded as acquired stuttering: Rosenbek et al., 1978, Horner and Massey, 1983), e.g. "ha-ha-ha-ha-ha-ha-ha-hagaki (postcard)";

(2) word, e.g. "chuugoku (China)-chuugoku-chuugokuchuugoku-chuugoku";

(3) phrase, e.g. "nihon no souridaijin (the Prime Minister of Japan)-nihon no souridaijin"; (c) (a)

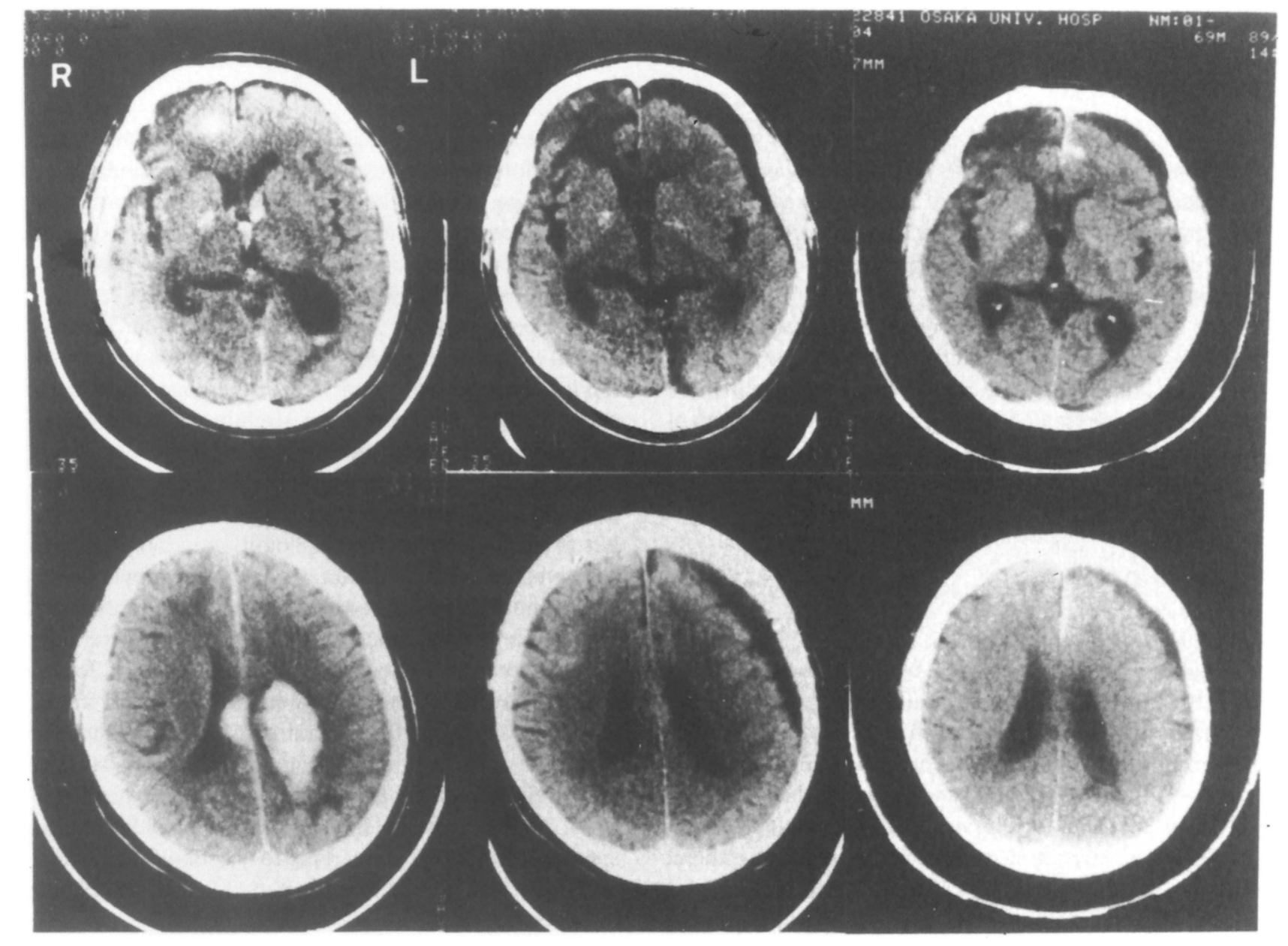

13 July, '89
11 August, '89
25 August. ' 89

FIG. 1. (a) CT scan on admission showing a small high density spot in the medial aspect of the right frontal lobe invading the cingulate gyrus and high density areas in the deep white matter of the left parietal lobe and the left lateral ventricle. (b) CT scan showing a low density area in the right frontal lobe and subdural effusion in the left frontal area. (c) CT scan showing a new small hemorrhage in the left medial frontal lobe encroaching on the straight gyrus and anteroinferior part of the cingulate gyrus.

242 Behavioural Neurology . Vol 5. 1992 


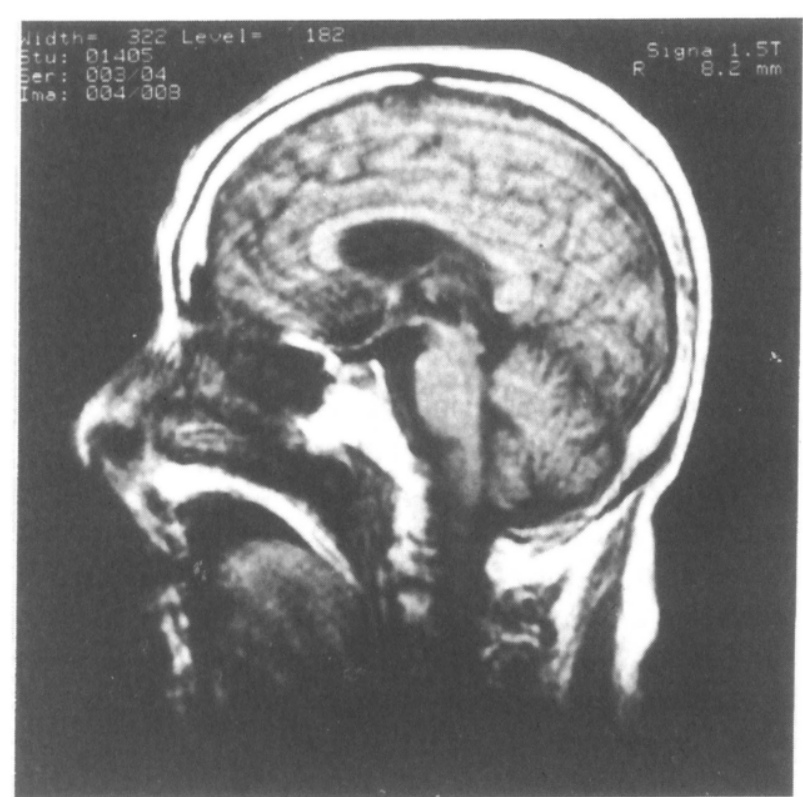

FIG. 2. MRI scan showing marked brainstem atrophy.

(4) vocalization in only one instance, e.g. "wooooooooooo, woooo0000000, woooo0000000".

It is noteworthy that the content changed when the examiner interrupted his palilalic speech, e.g. "naika (internal medicine)-naika-naika [the examiner cutting in: geka deshitakane? (Aren't you a surgeon?)] geka deshitakane".

In summary, this patient developed marked palilalia associated with pseudobulbar palsy and extrapyramidal signs following a small bleed in the anteroinferior part of the left medial frontal region in addition to a large lesion in the left parietal lobe and a small one in the right medial frontal lobe.

\section{Case 2}

A 59-year-old right-handed woman with a 15-year history of progressive loss of balance with repeated falls was seen on January 21, 1991. In 1986, she had been diagnosed as having Parkinson's disease in another hospital and treated with various anti-Parkinson drugs with no benefit. Recently, she could walk only with assistance.

On examination, her face was amimic and the speech was monotonous. She showed pseudobulbar palsy with dysarthria, marked nuchal rigidity, mild rigidity of the extremities, and general mental slowing. There was a mild snout reflex, bilateral Hoffmann's reflexes and brisk deep tendon reflexes. Both plantar responses were extensor. The orbicularis oculi reflex was brisk. She had "apraxia of lid opening". The pupils reacted normally to light. She was able to converge. Confrontation fields were normal. There was almost complete paresis of up-and-down gaze to pursuit and willed movement except for a few degrees of following downward movement. To a lesser extent, lateral gaze was involved. In contrast, doll's-head maneuvers revealed full conjugate movement in all directions. She showed poor balance and wide-based small-step ataxic gait with tendency to retropulsion. No aphasia, apraxia, or agnosia could be clinically detected. A magnetic resonance imaging (MRI) scan showed predominant brainstem atrophy (Fig. 2).

Although spontaneous speech production was reduced, she could answer to simple questions with marked palilalia. As well as palilalia, echolalia developed when she was addressed. There were no repetitions when she counted aloud. She reiterated syllables, a word, or phrases three to more than 15 times, but repetition of a syllable or a sentence was not observed. As she repeated, the rate of speech gradually increased and the loudness reduced. The last repetitions in a series were sometimes whispered ("palilalia aphone": Marie and Lévy, 1925), e.g. "mieru (I can see) - mieru - mieru - mieru - mieru - mieru - mieru - mieru mieru-mieru-mieru-mieru-mieru-mieru-mieru-(inaudible but her lips were still moving)". As in Case 1, her palilalia changed content when she was interrupted, e.g. "nana (seven)-nana-nana-nana-nana-nana-nana-nana-nana- [the examiner cutting in: niju kara san hiitara? (Subtract three from twenty?)] niju kara san hiitara-san hiitara-san hiitara".

Thus, she showed conspicuous palilalia with pseudobulbar palsy, extrapyramidal signs, retropulsion, and paresis of eye movement. The clinical diagnosis was felt to be progressive supranuclear palsy.

\section{Case 3}

A 69-year-old right-handed woman had changed in her personality and behavior over 1 year. She had become increasingly restless. She had displayed flattening of effect. At presentation on October 15, 1990, neurological examination was unremarkable except that she was slightly disinhibited and distractable. Responses were produced impulsively without thought. There was no evidence of visual agnosia, spatial disorientation or apraxia.

She had an almost normal performance on Mini Mental State Examination (26/30). Visuoperceptive and visuoconstructive tests did not disclose any abnormality. Although her speech was fluent, well articulated, and grammatically well structured, she showed striking palilalia. Grimacing or other involuntary movements did not occur. Echolalia, echopraxia and palikinesia were also observed. She did not seem to retain insight into her deficit. A MRI scan demonstrated marked right frontotemporal atrophy with left basal frontal atrophy (Fig. 3). A SPECT scan with ${ }^{99 m}$ Tc-hexamethylpropyleneamine oxime revealed markedly reduced uptake in the right frontotemporal convexity (Fig. 4). An EEG was normal.

She reiterated phrases or a sentence three to nine times with constant loudness and rate of speech as follows, but 
repetition of a syllable, syllables or a word hardly occurred, e.g. "jitenshya de mainichi itteru yo (I go by bicycle every day)-jitenshya de mainichi itteru yo-jitenshya de mainichi itteru yo-jitenshya de mainichi itteru yo""yonban ka? (Is it fourth?)-yonban ka?-yonban ka?-yonban ka?-yonban ka?-yonban ka?-yonban ka?-yonban ka?-yonban ka?"

Unlike the former two cases, the content of her palilalia did not change even after palilalic speech was interrupted e.g. "kore de eeno? (Is it all right?)-kore de eeno?-kore de eeno?-kore de eeno?-[her daughter cutting in: sensei no hanashi o kiite kara (You have to listen to the doctor first)] kore de eeno?-kore de eeno?-kore de eeno?-kore de eeno?-[her daughter cutting in: sensei no hanashi o (I am asking you to listen to the doctor)] kore de eeno?-kore de eeno?-kore de eeno?-[the examiner cutting in: sore de iikedo (I think it's all right)] kore de eeno?-kore de eeno?kore de eeno?"

Thus, she showed striking palilalia and alteration in her personality with marked right frontotemporal atrophy. She was diagnosed as having probable Pick's disease.

\section{DISCUSSION}

Palilalia is a striking but relatively rare speech disorder. It has been reported in pseudobulbar palsy (Dupré and Savoureux, 1914) and some Parkinson syndromes such as postencephalitic Parkinsonism (Sterling, 1924; Marie and Lévy, 1925) and idiopathic Parkinson's disease (Pick, 1921). It also occurs in patients with post-traumatic encephalopathy, paramedian thalamic and midbrain infarcts
(Hasegawa et al., 1986; Yasuda et al., 1990), cerebral infarction (Sato et al., 1991), intracerebral hemorrhage (Ibayashi et al., 1990), familial idiopathic cerebral calcifications (Boller et al., 1973) and degenerative diseases, such as Pick's disease (Caron, 1934; Guiraud, 1936; Hamanaka, 1986; Otsuka et al., 1988), Alzheimer's disease (Frey, 1914) and progressive supranuclear palsy (Lebrun et al., 1986; Uyama et al., 1989).

Sterling (1924) divided palilalia in postencephalitic Parkinsonism syndrome into two types: palilalie spasmodique resp. hétérolalique and palilalie atonique resp. homolalique. The former is characterized by compulsive reiteration of utterances with increase in its rate and decrease in its volume. The latter is characterized by reiteration of utterances with constant rate, occasionally alternating with periods of silence. Since then, cases of palilalia have been reported according to this classification.

Palilalie hétérolalique has mostly been described in cerebrovascular disease with pseudobulbar palsy such as Case 1 or Parkinson syndrome as in Case 2 and palilalie homolalique has been mainly reported in Pick's disease (Caron, 1934; Guiraud, 1936; Hamanaka, 1986; Otsuka et al., 1988) such as Case 3, although both Sterling's original cases had Parkinsonism. In the cases of Pick's disease, palilalia has been associated with stereotypy and some authors described it as autoecholalia (Caron, 1934; Guiraud, 1936; De Ajuriaguerra and Garcia Badaracco, 1955). Besides cases of Pick's disease, palilalie homolalique has been described in several cases of Parkinsonism (Uyama et al., 1989) as a Sterling's case. In almost all of these

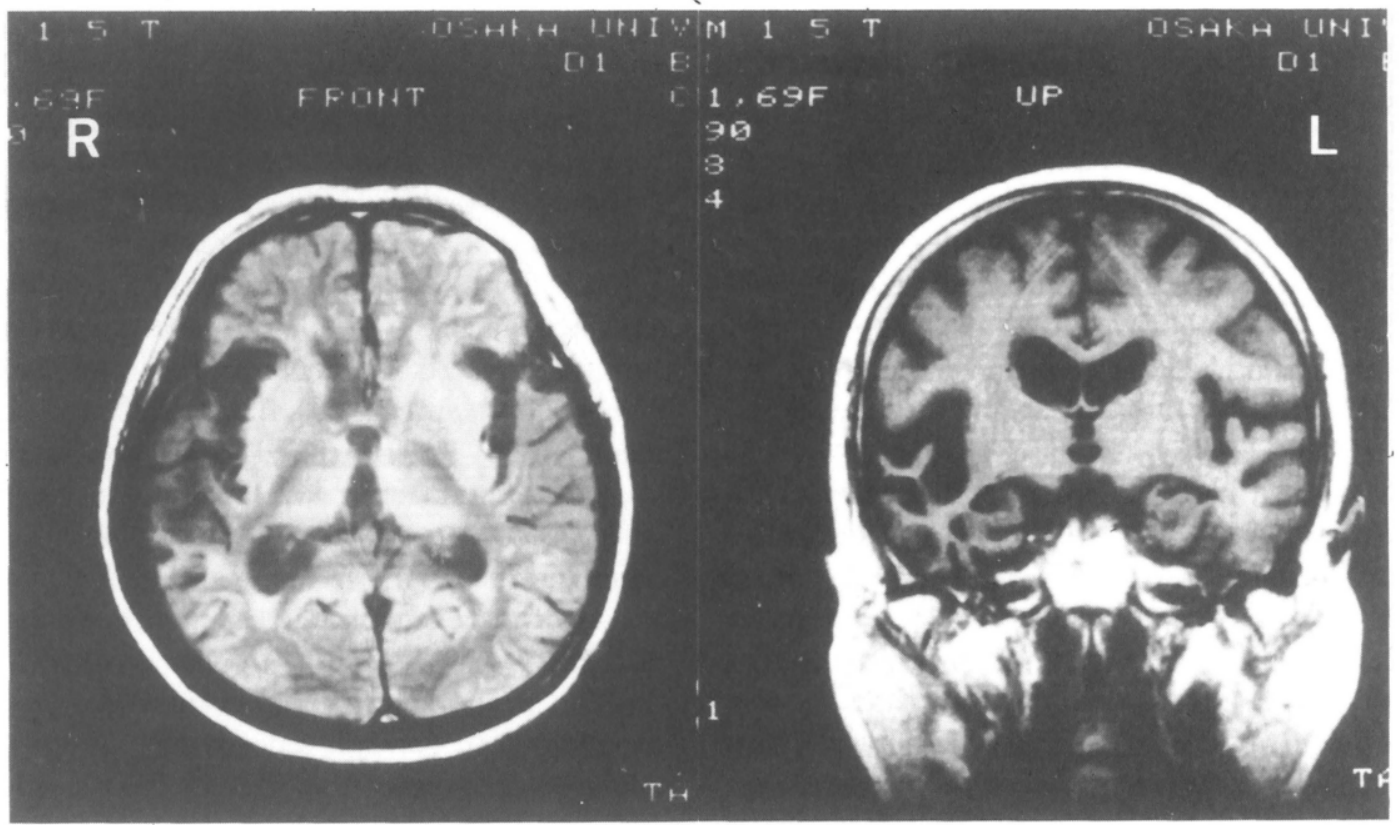

FIG. 3. MRI scan showing marked right frontotemporal atrophy. 


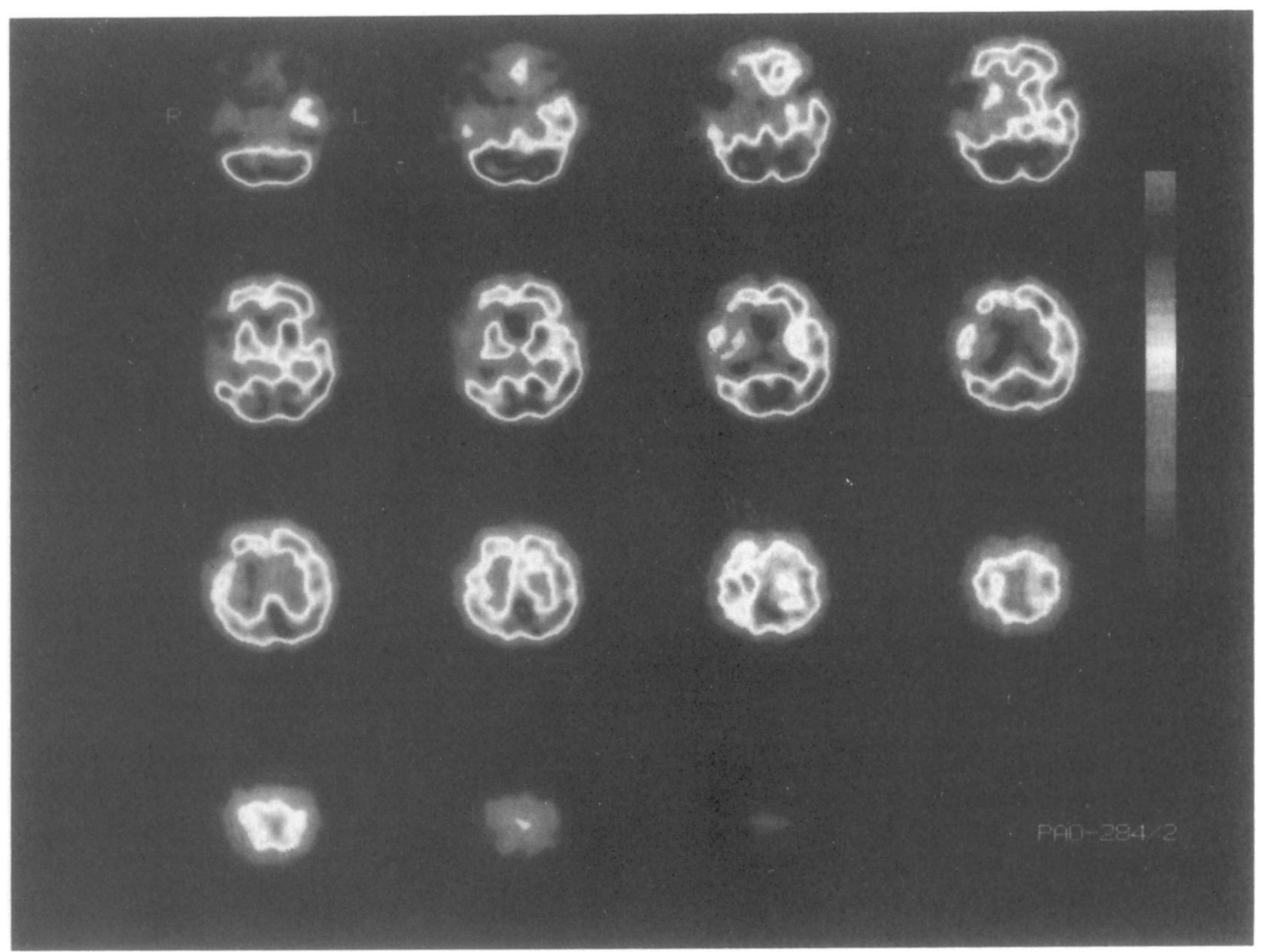

FIG. 4. SPECT scan showing striking reduced uptake in the right frontotemporal convexity.

cases, however, reiteration occurred only a few times, hence it seems difficult to determine to which groups they actually belong.

The palilalia in Cases 1 and 2 was characterized by an increase in its rate and decrease in its volume. Moreover, it changed its content when the examiner interrupted the palilalic speech by the patient reiterating part of the examiner's speech. On the other hand, the palilalia of Case 3 is characterized by constant rate and volume and an absence of change by interruptions.

"Spasmodic, heterophonic palilalia" may be related to "festination" of Parkinsonian gait, while "atonic, homophonic, autoecholalic palilalia" may be related to stereotypy. In order to differentiate these two types, it might be useful to determine whether the content of palilalia changes or not after interruptions.

Are there anatomical differences between these two types of palilalia? The neuroanatomical basis of palilalia is still unclear, although many authors have suggested that palilalia is an expression of disturbance in the basal gan- glia (Hamanaka, 1986). In some cases, however, palilalia was attributed to damage to the frontal lobe, especially its medial aspect. Recently, cases of paramedian thalamic and midbrain infarcts (Hasegawa et al., 1986; Yasuda et al., 1990) with palilalia have been reported. In Case 1, mild palilalia developed after a hemorrhage in the right medial frontal lobe. He became more palilalic after bleeding in the left medial frontal lobe. Accordingly, it may be suggested that in Case 1 bilateral lesions of the medial frontal lobe, especially the anterior part of the cingulate gyrus were mainly involved in the development of "spasmodic, heterophonic palilalia". But it is uncertain whether his palilalia can be ascribed exclusively to the bilateral medial frontal lesions since he also had extrapyramidal signs in his left extremities, indicating damage in the basal ganglia. In Case 2, her palilalia is likely to be related to dysfunction of the brainstem and basal ganglia which are predominantly affected in progressive supranuclear palsy. The involvement of the basal ganglia, medial frontal structures, and paramedian thalamus could produce "spas- 
modic, heterophonic palilalia" considering the multiple anatomical connections among these structures (Carpenter and Sutin, 1983). On the other hand, in Case 3, "atonic, homophonic, autoecholalic palilalia" seems to be based on the atrophy of the frontotemporal convexity. Palilalie homolalique has been mainly reported in Pick's disease (Caron, 1934; Guiraud, 1936; Hamanaka, 1986; Otsuka et al., 1988) and could be associated with stereotypy. Besides Pick's disease, palilalie homolalique was reported in a case of intracerebral hemorrhage due to head trauma that was restricted to the cortex of the right frontal convexity and its underlying white matter (Ibayashi et al., 1990) and in a case of hemorrhagic infarction restricted to the cortex of the left infero-posterior frontal convexity (Sato et al., 1991). Accordingly, the frontotemporal convexity which is commonly affected in Pick's disease might be involved in the development of "atonic, homophonic, autoecholalic palilalia.

\section{Acknowledgements}

We are indebted to Kazuo Hashikawa, Nobuo Handa and Masayasu Matsumoto, First Department of Internal Medicine, Osaka University Medical School, for providing an opportunity to examine Case 1. We also would like to express our appreciation to Prof. Tsuyoshi Nishimura, Department of Neuropsychiatry, Osaka University Medical School, and Prof. Junzo Shiraishi, Faculty Health and Sport Science, Osaka University.

\section{REFERENCES}

Boller F, Boller M, Denes G, Timberlake WH, Zieper I and Albert M (1973) Familial palilalia. Neurology, 23, 1117-1125. Caron M (1934) Etude clinique de la maladie de Pick. Thése, Paris.

Carpenter MB and Sutin J (1983) Human Neuroanatomy, 8th Edn. Williams \& Wilkins, Baltimore.

De Ajuriaguerra J and Garcia Badaracco J (1955) Contribution a l'étude des désorgainsations conjointes de la parole et du mouvement. Encéphale, 44, 297-335.

Dupré E and Savoureux L (1914) Palilalie chez une pseudobulbaire. Revue Neurologique, 27, 453-456.
Frey E (1914) Beiträge zur Klinik und pathologischen Anatomie der Alzheimershen Krankheit. Zeitschrift für die Gesamte Neurologie und Psychiatrie, 27, 397-434.

Guiraud P (1936) Analyse du symptome de stéréotypie. Encéphale, 31, 229-270.

Hamanaka T (1986) Clinical Neuropsychiatry-Pathology of Consciousness, Intelligence, and Memory, pp. 261-281. Igaku-Shoin, Tokyo.

Hasegawa O, Kobayashi H, Yoshii Y and Kaneko Y (1986) A case of palilalia with paramedian thalamic and midbrain infarcts. Neurological Medicine, 24, 573-577.

Horner J and Massey EW (1983) Progressive dysfluency associated with right hemisphere disease. Brain and Language, 18, 71-85.

Ibayashi K, Tanaka R, Tsuruoka H and Okada K (1990) Palilalia after traumatic intracerebral hemorrhage (a case report). Higher Brain Function Research, 10, 9-15.

Lebrun Y, Devreux F and Rousseau J (1986) Language and speech in a patient with a clinical diagnosis of progressive supranuclear palsy. Brain and Language, 27, 247-256.

Marie P and Lévy G (1925) Un singulier trouble de la palole: la palilalie. Monde Médical, 35, 329-344.

Otsuka A, Hadano K, Shigematsu K and Kamo H (1988) On a case of senile dementia with echopalilalia. Higher Brain Function Research, 8, 299-304.

Pick A (1921) Die Palilalie, ein Teilstück striäter Montilitätsstörungen. Abhandlungen aus der Neurologie, Psychiatrie, 13, 178-224.

Rosenbek J, Messert B, Collins M and Wertz RT (1978) Stuttering following brain damage. Brain and Language, 6, 82-96.

Sato M, Goto T and Watanabe K (1991) Transcortical sensory aphasia and palilalia following left frontal lesion: a case report. Japanese Journal of Neuropsychology, 7, 202-208.

Souques MA (1908) Palilalie. Revue Neurologique, 6, 340-349.

Sterling W (1924) Palilalie et le symptome "linguosalivaire" dans le Parkinsonisme encéphalitique. Revue Neurologique, 1, 205-220.

Uyama E, Katahira T, Okada H, Hashimoto $\mathrm{Y}$ and Araki S (1989) Palilalia associated with progressive supranuclear palsy. Clinical Neurology, 29, 617-621.

Yasuda Y, Akiguchi I, Ino M, Nabatabe $\mathrm{H}$ and Kameyama $\mathrm{M}$ (1990) Paramedian thalamic and midbrain infarcts associated with palilalia. Journal of Neurology, Neurosurgery and Psychiatry, 53, 797-799. 


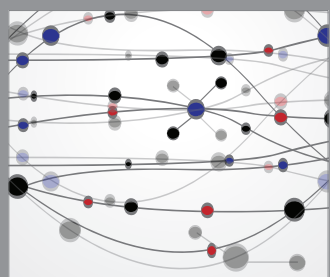

The Scientific World Journal
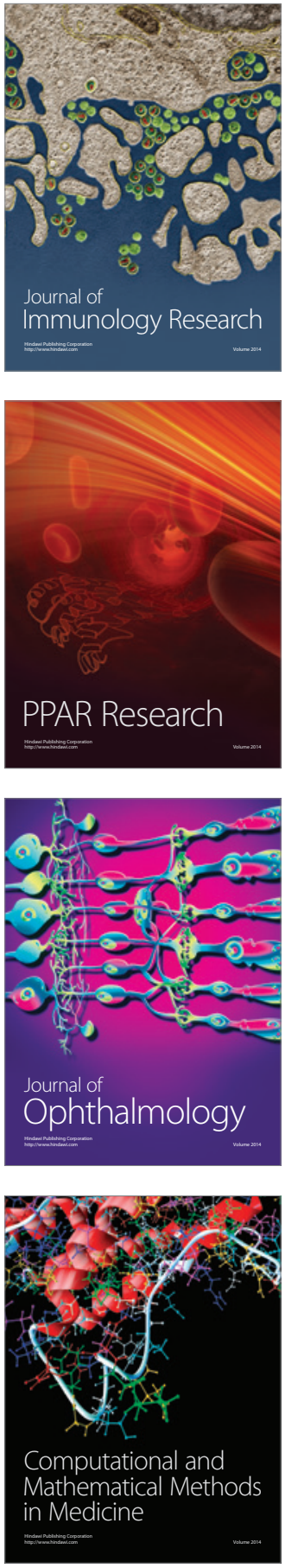

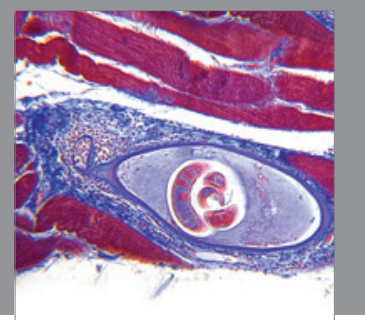

Gastroenterology

Research and Practice
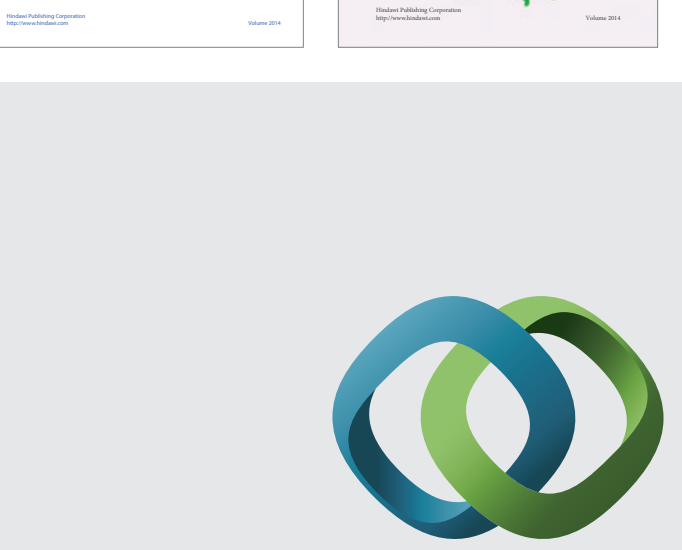

\section{Hindawi}

Submit your manuscripts at

http://www.hindawi.com
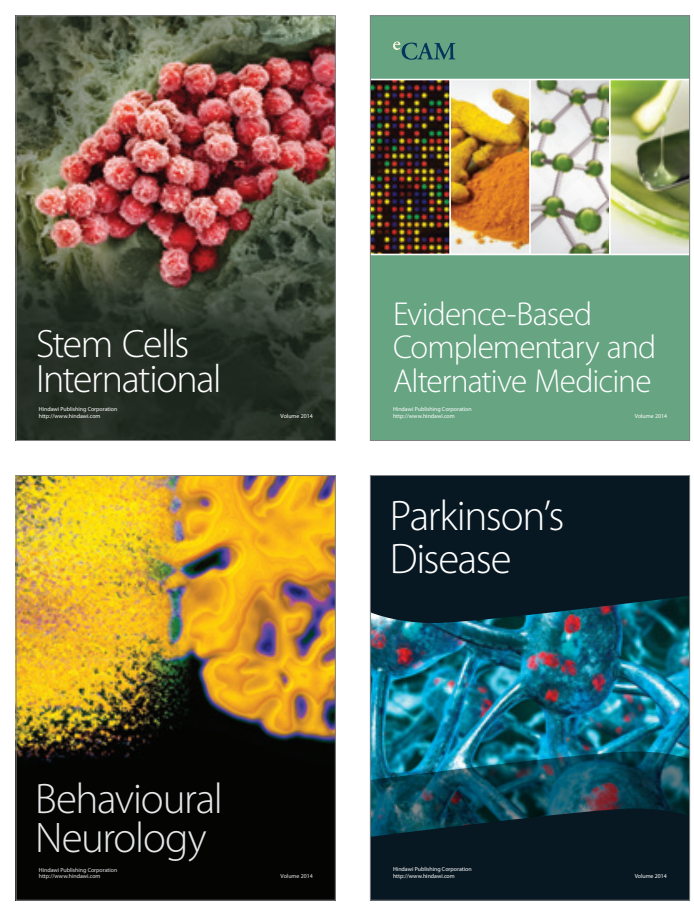

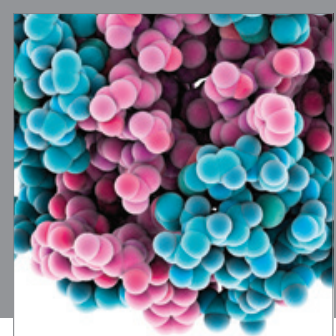

Journal of
Diabetes Research

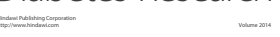

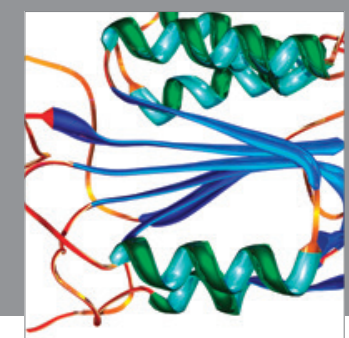

Disease Markers
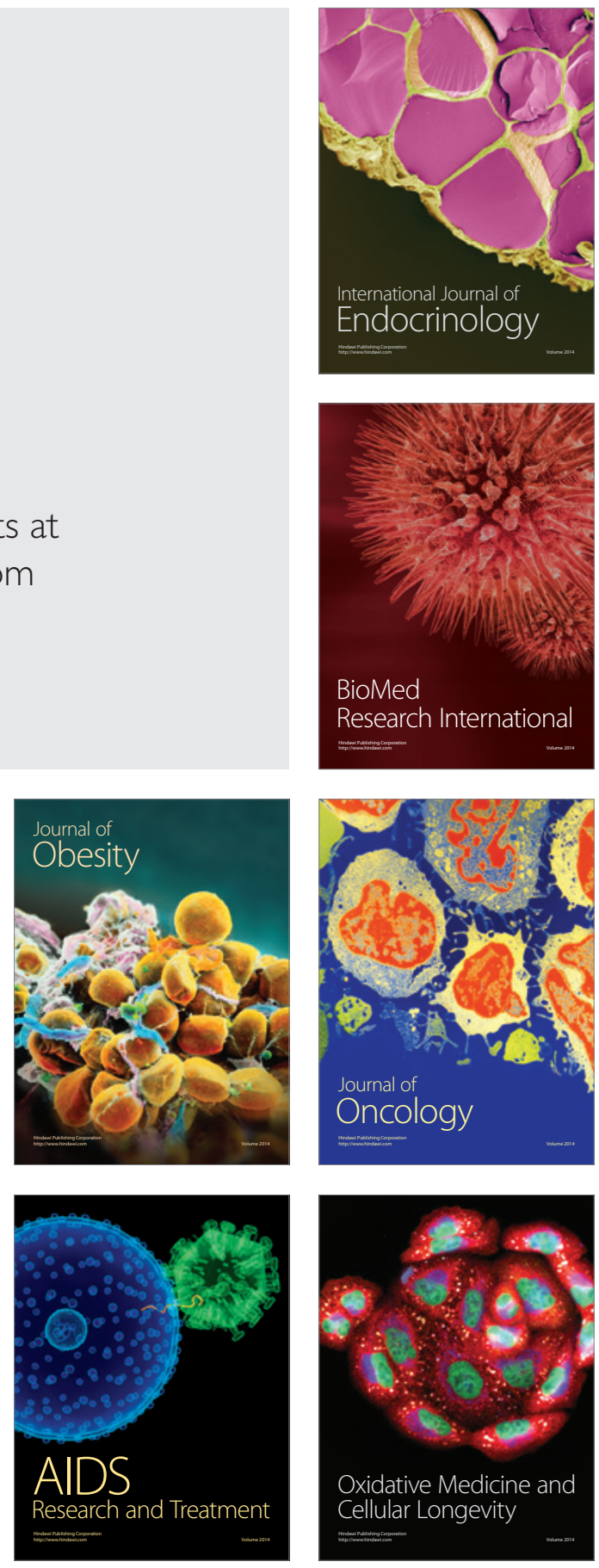